\title{
A Case Study of Success in Phasing out Policy of Instantaneous Water Heater in Australia and Feasibility in Thailand
}

\author{
Suttinee Jingjit and Kua-anan Techato
}

\begin{abstract}
This paper discusses the original, successful and effect of phasing out policy of instantaneous water heater in Australia. This can be applied for Thailand in order to phase out instantaneous water heater as a milestone. Hence, this work focuses on shifting from instantaneous water heater to heat pump and solar water heater. Thailand is suitable for these technologies because the high level of solar radiation is free from the sun. Many large buildings normally use heat pump but not popular in household. The important factors for consumers in Thailand are education and realization of energy saving and global warming issue. The knowledge of technician and consultant have to be developed for the new technologies. Phasing out policy of instantaneous water heater can be done under the supporting of Thai government, especially in term of subsidy for the high investment cost.
\end{abstract}

Index Terms - Phasing out policy, instantaneous water heater, Energy saving, Conservative energy.

\section{INTRODUCTION}

A common interesting topic presently regarding environmental issue is the global warming under Kyoto Protocol. Many approaches are announced in order to reduce greenhouse gas such as carbon footprint, carbon credit, green label, energy efficiency labels and etc. One of the most popular campaign is to reduce the electricity consumption. Especially, the old design of the electric devices with high power was obligated to be phased out and replaced by the new technologies such as:

1) "China Energy-Efficiency Refrigerator Project" from Dec 1999 to June 2006 that the old technology was replaced by the new one with 2 times-lower energy consumption than the existing [1].

2) "Lamp Phasing Out Legislations" from Jan 2012 to July 2014 by stopping the manufacturer for $100 \& 75$ watt incandescent and T12 Linear Fluorescent Lamps and Standard Halogen PAR Lamps in U.S. [2].

Australia endorsed the Kyoto Protocol in December 2007 to United Nations Framework Convention on Climate Change. From the UN Climate change conference (COP18 CMP8) on 8 December 2012 at Doha, Qatar. Most of Annex I countries

Manuscript received October 27, 2016; revised February 5, 2017. This work was supported by the Research and Researchers for Industries (RRi) $\mathrm{Ph} . \mathrm{D}$. grant, by the Thailand Research Fund under the Office of the Prime minister, Royal Thai government with Advance Thermo Solution Co., Ltd. under Grant PHD58I0032.

Suttinee Jingjit and Kua-anan Techato are with the Faculty of Environmental Management, Prince of Songkla University, Hatyai, Songkhla, Thailand (e-mail: kuaanan.t@psu.ac.th). have to reduce GHG emission $20-30 \%$ by 2020 from the reference year 1990 [3]. Australia's target is to cut GHG emission 5\% below 2000 levels by 2020 or $525 \mathrm{Mt} \mathrm{CO}_{2}$-e in 2020 [4].

The Climate Change and Energy Policy (CCEP) of Australia has prepared a preliminary target (Voluntary Target) to reduce greenhouse gas emissions to be 72 million tons in 2020 or about $18-21 \%$ compared to the business as usual (BAU) case abide by the meeting of Ad Hoc Working Group on Further Commitments for Annex I Parties under the Kyoto Protocol (AWG-KP) in reducing $\mathrm{CO}_{2}$ emissions by $450 \mathrm{ppm}$. The developing countries agreed to take National Appropriate Mitigation Actions (NAMAs) to address the urgent need to reduce global emissions lower than the BAU $15-30 \%$ in 2020 [3]. Thailand ratified to Kyoto Protocol in August 2002 [5] and approved to be the $58^{\text {th }}$ of developing country to voluntarily submitting of NAMAs. Thailand proposed to reduce GHG emission between $7-20 \%$ below projections for 2020 [6]. Thailand set three plans for saving the energy consumption and supporting the alternative and renewable energy under responsible by Ministry of Energy:

- REDP (The Renewable Energy Development Plan), to use renewable energy $20.3 \%$ of total energy in 2022 [7].

- AEDP (The Alternative Energy Development Plan), to use alternative energy $30 \%$ which can reduce energy from fossil fuel 39,388 ktoe and 140 million tons $\mathrm{CO}_{2}$ [8].

- EEDP (The Thailand 20 - Year Energy Efficiency Development Plan), to reduce energy intensity $25 \%$ in 2030 baseline 2005 [9].

\section{Australia Issue}

\section{A. Greenhouse Gas Emission}

Electric storage water heating emits almost a quarter of greenhouse gas from Australian households (refer with: Fig. 1). Electric hot water system produces around four tons of greenhouse gases every year. That is equivalent to the running an average 10 cars for a year [10]. Over $80 \%$ of electricity is generated from coal, $15 \%$ from natural gas and only $3 \%$ from renewables. Hence, an alternative water heating options such as heat pump, natural gas and solar collector can reduce greenhouse gas emission from water heater by $50-60 \%$ [11].

As mentioned above, under the second commitment of Kyoto protocol (period 2013 - 2020), Australia agreed to reduce the GHG emissions by $5 \%$ below the 2000 level by 2020. The emissions in 2000 were $559 \mathrm{Mt} \mathrm{CO}_{2}$-e, so achieving the target will mean holding emissions to $530 \mathrm{Mt}$ $\mathrm{CO}_{2}$-e in 2020. Without any emission projects, Australia's 
emissions expect to reach $656 \mathrm{Mt} \mathrm{CO}_{2}$-e in 2020 that higher than target $126 \mathrm{Mt} \mathrm{CO}_{2}$-e or $17 \%$ increase on $1990-2000$ level (refer with: Fig. 2) [12].

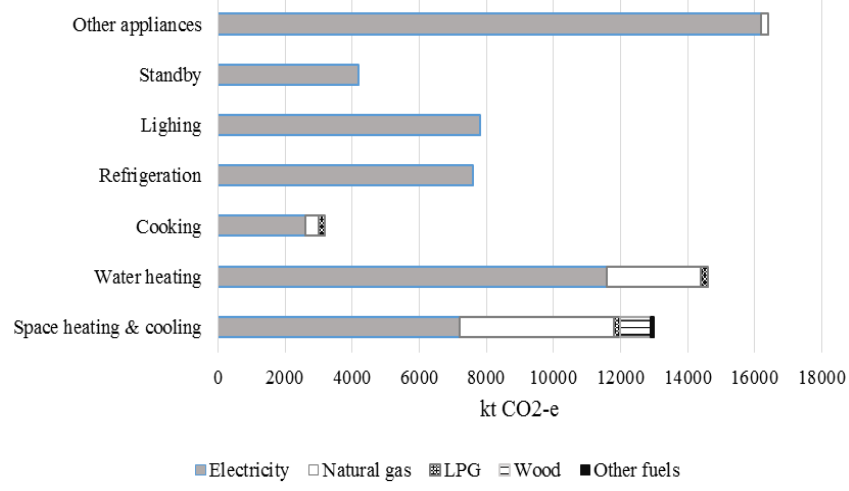

Fig. 1. Greenhouse gas emissions from residential sector energy use in Australia 2008

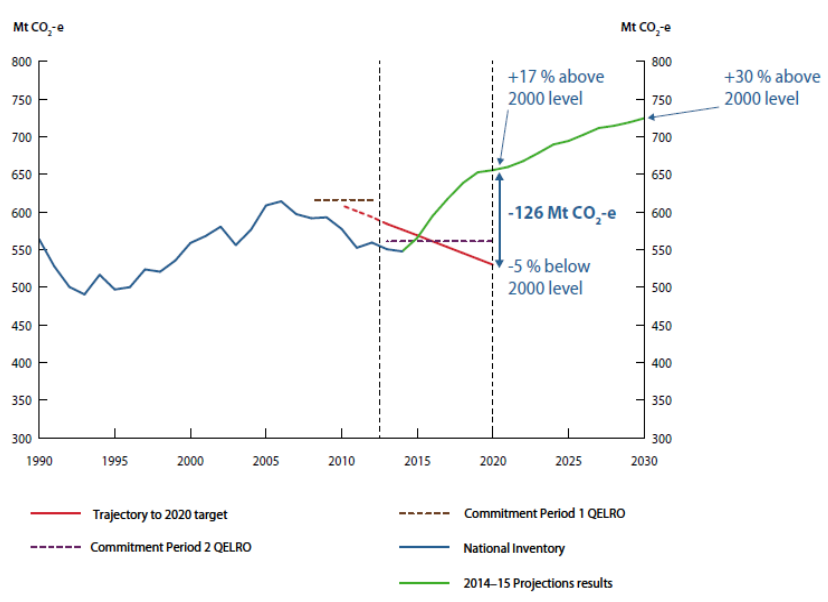

Fig. 2. Australia's emission trends, 1990 to 2030.

\section{B. Domestic Water Heating in Australia}

The Australian research showed that the household water-energy system factor of Australian can be described in term of 'human' (occupancy and behavioral) and 'Physical' (technological, structural and environmental) attributes [13]. The Australian residential was distinguished into 3 types; $83 \%$ class $1,16 \%$ class 2 and $1 \%$ other types. Class 1 refer to the house of single family that most of them has at least 1 water heater. For Class 2, it is apartments of multifamily, $60 \%$ of them have their own water heater system and $40 \%$ take hot water from the central system [11]. Most of water heater system in Australia is instantaneous water heater (IWH) due to lower price than alternative system such as solar collector and heat pump. Thus, the Australian government rebates and supports other capital cost for solar and heat pump water heaters.

\section{Interventions Water Heaters Market}

The Australian government intervened the water heaters market by enforces the energy labelling or MEPS. The Minimum Energy Performance Standards (MEPS) is appliances specific minimum level of energy performance. MEPS are regulated for products sold in Australia and New Zealand which must be registered through an online database and meet a number of legal requirements [14].

The IWH is popular because of the reasonable price that most population can reach it while the price of solar and heat pump water heater have very high capital cost. The government realized and solved the barrier through various incentive schemes. Consumer get reduces the purchase price by $900-1,400$ \$AUD (1.3 \$AUD/\$US) under the Renewable Energy Target (RET) scheme [15]. The second capital subsidy was instituted available only to householders replacing an existing electric water heater with a solar or a heat pump varies by States. The buyers get almost $75 \%$ of the capital cost back in some States [11].

Other inventions of the water heaters market are providing a range of information and education, industry training, innovative support and call center for water heating (example: hotwaterinahurry.com.au or 1300426468 ) [16].

\section{Phasing Out Policy}

The Ministerial Council on Energy (MCE) agreed to initiate "National Hot Water Strategic Framework (MCE 2008)" in December 2008. This framework focuses on the GHG reduction through water heater usage. The government specified the MEPS for water heaters together with phasing out of IWH [15]. It can save the lifetime cost, the electricity bill to household and significant $\mathrm{CO}_{2}$ reductions. For Class I, the first stage (during 2010), IWH will no longer be able to be installed in any new homes and where there is access to piped natural gas except where an exemption applies. Second stage (during 2012), IWH will no longer be able to be installed in any homes [17]. For Class 2, all new apartments were prohibited to use of IWH from 2013 while the existing apartments had to replace the IWH in between $2018-2020$ (see Table I).

\begin{tabular}{lll}
\multicolumn{2}{c}{ TABLE I. THE IMPLEMENTING OF IWH PHASE OUT } \\
\hline \multicolumn{1}{c}{ New } & Existing \\
\hline Class 1 & 2010 & 2010 \\
& All dwellings & $\begin{array}{l}\text { Dwellings in a gas } \\
\text { reticulated area } \\
\end{array}$ \\
& & 2012 \\
& & All dwellings \\
\hline Class 2 & 2013 & $2018-2020$ \\
& New dwellings with access to piped & All dwellings \\
& gas & \\
& $2013-2015$ & \\
& New dwellings without access to & \\
& piped gas & \\
\hline
\end{tabular}

In the present situation, the IWH is the most popular water heater type because of lower price. The number of solar water heater and heat pump are slightly increasing in the group of energy conservatives. The legislation to phase out IWH has impact to the disappearance of IWH in 2020, when the last of the existing units retires from service (refer with: Fig. 3). The main objective of this policy is to reduce the GHG emissions compared with the BAU case. The estimate in 2020, the phase out policy will reduce GHG emissions approximately 4.2 4.3 million tons of $\mathrm{CO}_{2}$-e per annum compared with the $\mathrm{BAU}$ case. It can reduce $\mathrm{GHG}$ emissions from water heating by

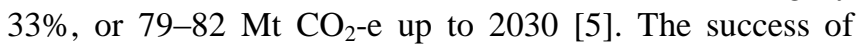
phasing out policy is not only the GHG emission reducing but the energy consumption also significantly reduces. The alternative water heater (gas, LPG, solar and heat pump) are high efficiency and low power compared to IWH. It can decrease of the household electricity bill also. 

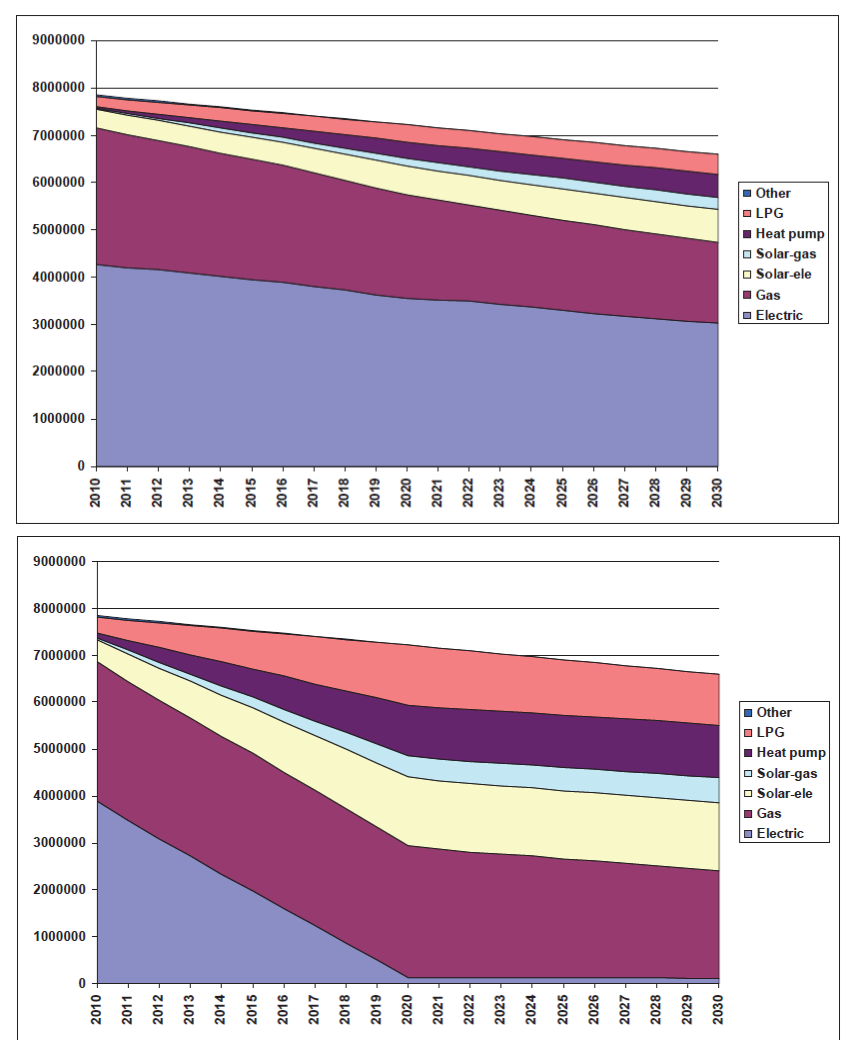

Fig. 3. Projected number of water heaters installed in Australian houses, 2010-2030 with (bottom) and without (top) phase out of IWH.

\section{E. Impact to Stakeholder}

The phasing out policy directly effect to the existing IWH industrial including manufacturer supplier and plumber \& installer and the household as owners - renters of house and apartment.

\section{1) Industrial}

As the legislation, the IWH would reduce by $50-70 \%$ within 2012 and this market will cease in 2020. The main Australian manufacturing sites for water heaters are Rheem, Welshpool, Scoresby, Moorabbin, Dux, Beasley and Saxon [15]. Most of them have recently expanded capacity production for alternative water heater types to remain in the market. All the storage pressure tanks used in many water heaters type are made in Australia, so they can shift market share from electric storage to others. The manufacture of pressure tanks could continue to be supplied as the manufacture of small electric water heaters that their products could still be used as supplementary water heaters. Because of the alternative water heaters have long life, the service of repair would decrease. While the plumber worker are necessary for gas and LPG water heaters installation. However all water heaters require electrical consultant in high demand. The changing of water heating market require many additional skills, it starts many new jobs such as solar experts, refrigeration experts and workers to lift the collectors on to the roof.

\section{2) Household}

All existing house was required to replace their existing IWH when it fails by alternative water heaters with 10 years from 2010. The beginning of implementation, most of homeowner aware of phasing out. They faced to the high capital cost of alternative water heaters as solar collector and heat pump, but low running cost. However, the capital cost could be minimized through subsidy up to $75 \%$ from the government fund or interest-free loan. The capital cost of LPG is lower than solar collector and heat pump but its higher running cost which no subsidy program [18]. After the replacing, homeowner recognized as the saver electricity bill and energy saving. Options to encourage owners of electric water heaters to think about alternative technologies would also be useful. In 2013, Australia ranked sixth for new installations of solar water collectors, just behind the United States [19]. In case of the house or apartment owner for rental, after the alternative water heaters set, the rental slightly increased.

However, the replacing of alternative technology can confound consumer behavior such as the rebound effect that households consume more electricity due to the electricity bill saving [20]. The preliminary success of Australia government might benefit for other countries as a case-study to follow. Like phase out instantaneous water heater in Thailand that should be measured all impacts and make an own proposal to complete.

\section{THAILAND ISSUE}

Approximately $70 \%$ of electricity in Thailand is generated from natural gas. The electricity consumption in Thailand has continuously increased in recent years. In 2014, the electricity consumption reaching the amount of 168,620 Gigawatt-hours (GWh) while the generation was $180,945 \mathrm{GWh}$. The residential sector is the highest consumer about $89 \%$ [21]. Thailand's value of electricity consumption had been increasing every year (refer with: Fig. 4). In 2014, the expenditure of electricity consumption approximately 662 billion Baht (35 THB/\$US) which increased 4 times in 15 years. From the survey in 2015, the average expense in 1 household is 21,157 Baht (The energy expense share of 10\%). The expense in Energy, the major is $67 \%$ from petroleum product while $31 \%$ comes from electricity consumption [22].

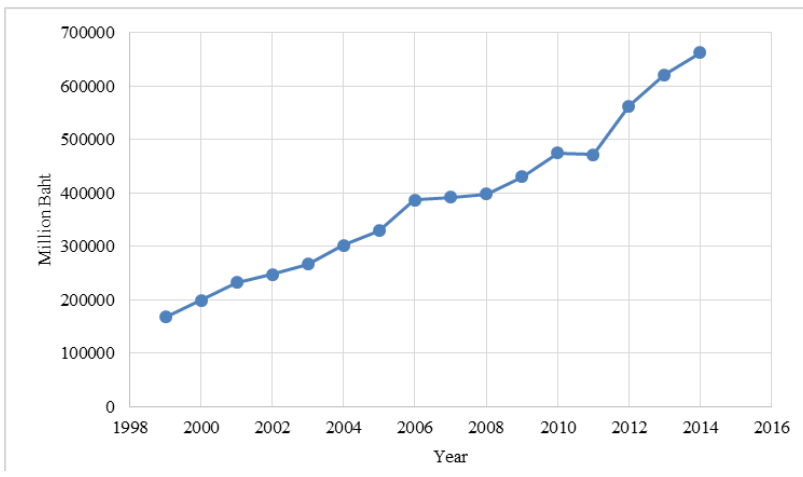

Fig. 4. Expenditure on electricity consumption in Thailand (1999 - 2014).

At present, almost every people used appliances in order to have the comfortable living such as refrigerators, washing machines, air conditioner and water heater. Among household appliances, the water heater has the highest power as $3.5-4.5$ kilowatt $(\mathrm{kW})$ while refrigerators, washing machines, air conditioner lower than $1 \mathrm{~kW}$. The IWH was replaced by alternative water heater system such as solar collector and heat pump in many countries. As above, the IWH has high 
power consumption and emits high amount of GHG. Thailand should follow the phasing out policy of Australia and replace by alternative water heater.

\section{A. Feasibility of Alternative Water Heater Technologies}

Thailand is located on equatorial zone that can get the ongoing and constant solar radiation throughout the year. The solar radiation of Thailand is approximately $18 \mathrm{MJ} / \mathrm{m}^{2}$-day. Therefore, Thai government has encouraged the solar radiation technologies such as for electricity, water heater and for drying [23].

In hotels, hospitals and factories need to use the huge system of hot water for their business. They use heat pump as heat exchanger with residual heat from many devices such as boiler. The heat pumps heat the water by generally sources such as air, water and ground. Especially, the air source heat pumps use the ambient air outside the building that is no cost. It will improve the energy efficiency of hot water system by $40-80 \%$ compared to electric hot water system [24].

\section{B. The Alternative Water Heater Market in Thailand}

The Solar Water Heater (SWH) has started in Thailand for 25 years ago that installed on public hospital by Thai government. Previously, Thailand imported solar collectors from Australia, nowadays the imported SWH parts and collectors have shifted to China, Germany and Israel. However, SWH is not a popular for most consumers, only 25 companies operating in the market. The lack of knowledge of installers and users in Thailand will be a big problem. There is very high percentage of system failure shortly after installation in Thailand [23]. Four academic institutes in Thailand had service for indoor and outdoor solar thermal collector but it is not continuous in operation. The quality label and certification for solar thermal are not available in Thailand. The Thai Customs Department required to be exempted from the import tax for the importers of solar products in Thailand. The cost of solar system can be lower around $20 \%$ [25].

The heat pump market in Thailand started in 2002 from Thai government's subsidized $25-30 \%$ for the changing of existing hot water systems to heat pumps. This project is the pilot case for many hotels for water heater system changing. In several years ago, most of heat pumps in Thailand were imported from other countries because of its reliability. Later, the users found that imported and local heat pump are the same performance. New customer chose the local one which is cheaper. The water storage tank is the major cost of heat pump. There is no glass lining tank manufacturer in Thailand. It has to order from India, China or Europe [26]. Many manufacturers in Thailand had developed the system both reduce the cost of storage tank and increase the efficiency.

The important factors of heat pump development depended on the cost, performance and the customer behavior. Nowadays, there are many manufacturers or suppliers of heat pump in Thailand e.g. Quantum, Trane, Carolex, Big Red, BTP, Energy Master, Ecotech, Rheem, Pecol, and PAC.

\section{Supporting Factor for Phasing out}

The supporting factor for policy decision making can classify into 2 groups, environmental and economic factor.
The benefits from the phasing out that will push the project to the goal.

\section{1) Environmental factor}

The widely acknowledge benefit of SWH is in the potential of energy saving that can reduce the amount of electrical energy used for water heating. The depletion of fossil fuel are lower nearly $83 \%$ in UK [27] by solar collectors. It is also used in household sector that can reach $130 \mathrm{kWh}$ a month of the electricity saving per household in the South Africa [28]. The SWHs has direct effect to reduction in oil consumption of 71,907 L/year in Korea [29]. Japan assumed that SWH will be adopted in the category with the largest reduction in $\mathrm{CO}_{2}$ emissions [30]. $\mathrm{CO}_{2}$ emission approximately $200 \mathrm{~kg}$ will reduced by a $1 \mathrm{~m}^{2} \mathrm{SWH}$ collector area or it can save $67-70 \%$ $\mathrm{CO}_{2}$ emissions compared to a conventional system [31].

Furthermore, heat pump system is an alternative of water heating in various industrial, commercial and residential applications that consumes less electricity consumption. Its systems would have the effect of markedly changing the electricity load curve and reduce the power peaks in relation to electric systems [32]. For instance, 70\% of energy could be saved by heat pump in China, compared with the traditional electric water heater [33]. The U.S. uses 53\% less electrical energy and power than the business as usual (BAU) [34]. In South Africa, this alternative technology saved GHG emission by $60 \%$ [35].

\section{2) Economic factor}

The steady increase in the electricity costs from modern appliances raises the interest in the alternative technology especially IWH which have the high electric power. It should be instead of lower electric power such as SWH or heat pump that mentioned before. Both alternative water heater technologies become more attractive as the electric bill saving [36]. The electric bill can reach $47 \%$ monthly saving from the use of electricity backed-up SWH in Brazil [37]. In Lebanon, the country saved millions of dollars in avoiding new power plant costs and reducing the huge of the electricity bill for the consumer [38].

As mention before, SWH and heat pump technologies have high initial cost much more than the old water heating technology which hard to make a decision for investment especially the low income household. A government financial support is one of the most important factors for selection. The financial support by the government bodies in term of subsidy is considered necessary to encourage user. The subsidy scheme for alternative water heating technology is promoted in many countries such as Germany, Austria, Sweden, Australia and Netherlands [39].

The government of Thailand also has many projects for supporting their investment such as ESCO (Energy Service Company) Fund and Revolving Fund. Thai government also set the project that called "Cost Base" in 2012 to encourage people use the electric appliance with high performance and energy saving which can discount tax up to $25 \%$ of their appliance price.

\section{The Economic Analysis}

The study of economic analysis of water heater technology changing in Thailand was investigated in household [40]. The 
existing water heater system is IWH that widely used in Thailand. Economic analysis of Payback Period (PP), Net Present Value (NPV) and Internal Rate of Return (IRR) was calculated under replacing IWH by SWH and heat pump (see Table II). Household need 9.56 years for payback in SWH installation that longer than heat pump. The NPV under 15 years is 23,130 Baht and IRR are $6.24 \%$ of SWH while 19,050 Baht and $9.59 \%$, respectively of heat pump which 10 years of all lifetime.

TABLE II. THE ECONOMIC ANALYSIS OF IWH REPLACED BY SWH AND HEAT PUMP IN THAILAND

\begin{tabular}{l|ccc}
\hline & $P P($ year $)$ & $N P V($ Baht $)$ & $I R R(\%)$ \\
\hline $\begin{array}{l}\text { Replacing by } \\
\text { solar water heater }\end{array}$ & 9.56 & 23,130 & 6.24 \\
\hline $\begin{array}{l}\text { Replacing by heat } \\
\text { pump }\end{array}$ & 6.25 & 19,050 & 9.59 \\
\hline
\end{tabular}

\section{CONCLUSION}

The main point of phasing out of IWH policy in Australia is to reduce GHG emission followed by the target of Kyoto Protocol (Phase II) that have to cut it $5 \%$ below 2000 levels by 2020. This policy is the implement policy to force the new and the existing households to install the alternative water heater systems such as solar collector and heat pump. Australian government set the most attractive program as subsidies up to $75 \%$ for customers. The target of this program is no more instantaneous water heater in Australia household after 2020. It can reduce GHG emissions approximately $4.2-4.3$ million tons of $\mathrm{CO}_{2}$-e per annum compared with the BAU case. However, the phasing out policy directly effect to industrial and household. The water heater market was replaced by alternative water heater systems. Many of manufacturers had to change their products. The plumber workers, electrical consultants, solar experts, refrigerator experts and normal workers are necessary for new installation. Because of the new investment, most of the house or apartment owner increased the rental. The household found the saving electricity bill after changing the water heater systems, which become the rebound effect to many consumers.

Thailand can replace the IWH by solar collector because of suitable physical geography of country. The solar radiation of Thailand is high. Many years ago, Thai government encouraged to use the SWH in hospital/hotel which need the high volume of hot water. Heat pumps have been used in large business. It can heat the water by ambient air, water and ground. With the expensive investment, Thai government set many projects for supporting such as ESCO fund, Revolving fund. The alternative water heater market in Thailand is not popular for household due to the high investment and no subsidy or any support program of Thai government. Anyhow, the economic analysis of alternative water heater for household can support the feasibility to change the technology.

Phasing out policy of IWH in Thailand can be done under the supporting of Thai government in term of subsidy for the high investment cost. According to the previous study, payback period of SWH and heat pump are 9.56 and 6.25 years respectively. Their NPV analysis found high value. However, the education and realization of energy saving and global warming issue is very important factor for consumer. The technician and consultant in Thailand have to be developed their knowledge for the new technologies.

\section{REFERENCES}

[1] United Nations, "Transformation of the refrigerator market in China," Case Studies of Market Transformation: Energy Efficiency and Renewable Energy, New York, 2007, pp. 1-13.

[2] The retrofit companies. (March 2013). When are your fluorescent lights being discontinued? [Online]. Available: http://blog.retrofitcompanies.com/blog/bid/242603/When-Are-YourFluorescent-Lights-Being-Discontinued

[3] United Nations, "Outcome of the work of the Ad Hoc working group on further commitments for Annex I Parties under the Kyoto protocol," presented at the Conference of the Parties serving as the meeting of the Parties to the Kyoto Protocol, 8th session, Doha, Qatar, November 26-December 7, 2012.

[4] The Conversation Media Group Ltd. (April 2014). Australia trounced Kyoto climate target, new report reveals [Online]. Available: http://theconversation.com/australia-trounced-kyoto-climate-target-ne w-report-reveals-25744

[5] United Nations. (2014). List of Non-Annex I Parties to the Convention [Online]. Available: http://unfccc.int/parties_and_observers/parties/non_annex_i/items/28 33.php

[6] Thailand Greenhouse Gas Management Organization. (2015). Greenhouse Gas news: Thailand makes a plan for reducing GHG follow by NAMAs [Online]. Available: http://www.tgo.or.th/2015/thai/news_detail.php?id=458

[7] The Renewable Energy Development Plan: REDP (2008-2022), Department of Alternative Energy Development and Efficiency, Ministry of Energy, 2011.

[8] Alternative Energy Development Plan: AEDP (2015-2036), Department of Alternative Energy Development and Efficiency, Ministry of Energy, September 2015.

[9] The Thailand 20-Year Energy Efficiency Development Plan: EEDP, Energy Policy and Planning Office Ministry of Energy, February 2011.

[10] A joint initiative of the Australian, State and Territory Governments, "Water heating, the environment and you," Factsheet, pp. 1-6.

[11] S. Williams and G. Wilkenfeld, "Phasing out greenhouse-intensive water heaters in Australia," Energy efficiency First: The Foundation of a low-Carbon Society, pp. 365-375, 2011.

[12] Australia's Emissions Projections 2014-15, Department of Environment, Australian Government, March 2015.

[13] A. B. Binks, S. J. Kenway, P. A. Lant, and B. W. Head, "Understanding Australian household water-related energy use and identifying physical and human characteristics of major end uses,' Journal of Cleaner Production, vol. 135, pp. 892-906, 2016.

[14] A joint initiative of Australian, State and Territory and New Zealand Governments. (2015). Legislative Framework. [Online]. Available: http://www.energyrating.gov.au/suppliers/legislation

[15] George Wilkenfeld and Associates with National Institute of Economic and Industry Research, "Phasing out greenhouse-intensive water heaters in Australian homes," November 2010.

[16] Hot water in a hurry. (April 2016). Hot water specialists: When you need hot water now! Available 24 hours -7 days in the Sydney metro area. [Online]. Available: http://hotwaterinahurry.com.au

[17] E. Halawa, K. C. Chang, and M. Yoshinaga, "Thermal performance evaluation of solar water heating systems in Australia, Taiwan and Japan - A comparison review," Renewable Energy, vol. 83, pp. 1279-1286, 2015

[18] Solarhart, "Australian solar hot water market," Australian Solar Energy Society, March 2010.

[19] Renewables 2015 Global status report, Renewable Energy Policy Network for the $21^{\text {st }}$ century, 2016.

[20] L. Havas, J. Ballweg, C. Penna, and D. Race, "Power to change: Analysis of household participation in a renewable energy and energy efficiency programme in Central Australia," Energy Policy, vol. 87, pp. 325-333, 2015.

[21] Energy Statistics of Thailand 2015, Department of Alternative Energy Development and Efficiency Ministry of Energy, 2015.

[22] Executive Summary: The Energy Consumption of Household in 2015, National Statistical Office, 2016.

[23] Guideline for Development and Investment in Renewable Energy; Part 2: Solar Energy, Department of Alternative Energy Development and Efficiency, Ministry of Energy, 2012. 
[24] Smartblocks. (2016). Install a heat pump system for hot water [Online] Available:

http://smartblocks.com.au/what-can-i-do/water-systems/upgrade-your -hot-water-system/5/

[25] Final Report: Market Development for Solar Thermal Applications in Thailand (SolTherm Thailand), The Joint Graduate School of Energy and Environment (JGSEE), King Mongkut's University of Technology Thonburi and International Institute for Energy Conservation (IIEC) and Institute for Solar Energy Systems (FRAUNHOFER ISE), July 2007

[26] K. Techato, "Heat Pump Market in Thailand," Energy Procedia, vol. 14, pp. 9-13, 2012.

[27] G. Benjamin and A. Azapagic, "Domestic solar thermal water heating: A sustainable option for the UK?" Renewable Energy, vol. 63, pp. 23-36, 2014.

[28] D. Georgi, W. G. J. H. M. van Sark, K. Blok, and O. Dintchev, "Solar water heating potential in South Africa in dynamic energy market conditions," Renewable and Sustainable Energy Reviews, vol. 16, no. 5, pp. 3002-3013, 2012.

[29] Yoo and J. Hyun, "Evaluation of solar hot water heating system applications to high-rise multi-family housing complex based on three years of system operation," Energy and Buildings, vol. 101, pp. 54-63, 2015.

[30] Y. Yohei, K. Akai, J. Shen, N. Fujimura, Y. Shimoda, and T. Saijo, "Prediction of photovoltaic and solar water heater diffusion and evaluation of promotion policies on the basis of consumers' choices," Applied Energy, vol. 102, pp. 1148-59, 2013.

[31] K. Soteris, "Thermal performance, economic and environmental life cycle analysis of thermosiphon solar water heaters," Solar Energy, vol. 83, no. 1, Elsevier Ltd: 2009, pp. 39-48.

[32] A. S. Vieira, C. D. Beal, and R. A. Stewart, "Residential water heaters in Brisbane, Australia: Thinking beyond technology selection to enhance energy efficiency and level of service," Energy and Buildings, vol. 82, pp. 222-36, 2014.

[33] J. Dong, Z. Zhang, Y. Yao, Y. Jiang, and B. Lei, "Experimental performance evaluation of a novel heat pump water heater assisted with shower drain water," Applied Energy, vol. 154, pp. 842-50, 2015.

[34] B. Magdalena, P. Erickson, B. Jenkins, and K. Kornbluth, "A comparative study of district and individual energy systems providing electrical-based heating, cooling, and domestic hot water to a low-energy use residential community," Energy and Buildings, vol. 92, pp. 306-312, 2015.
[35] E. D. Özdemir and J. Tomaschek, "Economic and environmental analysis of solar water heater utilisation in Gauteng province, South Africa," vol. 23, no. 2, pp. 2-19, 2012.

[36] R. Isabella and P. E. Khoury, "Lebanon's market for domestic solar water heaters: Achievements and barriers," Energy for Sustainable Development, vol. 17, no. 1, pp. 54-61, 2013.

[37] G. Thalita, R. Lamberts, M. Barbosa, and M. Urbano, "A procedure for analysing energy savings in multiple small solar water heaters installed in low-income housing in Brazil," Energy Policy, vol. 72, pp. 43-55, 2014.

[38] Houri and Ahmad, "Solar water heating in lebanon: current status and future prospects," Renewable Energy, vol. 31, no. 5, pp. 663-675, 2006.

[39] Z. Y. Wang, W. Yang, F. Qiu, X. Zhang, and X. Zhao, "Solar water heating: from theory, application, marketing and research," Renewable and Sustainable Energy Reviews, vol. 41, pp. 68-84, 2015.

[40] S. Jingjit and K. Techato, "The economic analysis of water heating technology in Thailand," Asia Pacific Journal of Science and Technology, vol. 21, no. 4, pp.70-77, 2016.

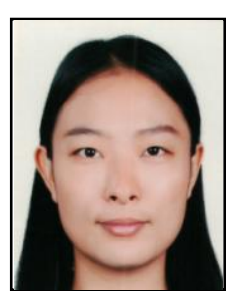

Suttinee Jingjit was born in Bangkok, Thailand, in 1987. She is now studying Ph.D. at Faculty of Environmental Management, Prince of Songkla University where she also finished her bachelor and master of Science in Biotechnology. Her research interests are renewable energy, alternative energy and energy saving.

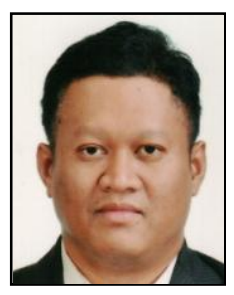

Kua-anan Techato was born in Yala, Thailand, in 1974. He is an associate professor at Faculty of Environmental Management, Prince of Songkla University. He is the Chair of master and doctora program in Sustainable Energy Management and assistant to the Director of the Energy System Research Institute. His research interests are Energy Conservation and Renewable Energy/Energy an Environmental Policy and Management Climate Change Adaptation by Bio-Energy Efficiency and Ecology (Green Roof, Wall, and Light Source) 